\title{
Efficacy and tolerability of lacosamide for secondary epileptic seizures in patients with brain tumor: A multicenter, observational retrospective study
}

\author{
JUAN MANUEL SEPÚLVEDA-SÁNCHEZ ${ }^{1}$, ANTONIO CONDE-MORENO ${ }^{2}$, \\ MANUEL BARÓN $^{3}$, JAVIER PARDO ${ }^{4,5}$, GASPAR REYNÉS $^{6}$ and ANTONIO BELENGUER ${ }^{7}$ \\ ${ }^{1}$ Neurooncology Unit, Hospital 12 de Octubre, 28041 Madrid; ${ }^{2}$ Department of Radiation Oncology, \\ Hospital Provincial de Castellón, 12002 Castellón; ${ }^{3}$ Hospital Universitario Fundación Alcorcón, 28922 Madrid; \\ ${ }^{4}$ Hospital Universitario Rey Juan Carlos, 28933 Madrid; ${ }^{5}$ Hospital Universitario Infanta Elena, 28342 Madrid; \\ ${ }^{6}$ Hospital Universitari i Politècnic La Fe, 46026 Valencia; ${ }^{7}$ Hospital General de Castellón, 12002 Castellón, Spain
}

Received November 11, 2016; Accepted February 3, 2017

DOI: $10.3892 / \mathrm{ol} .2017 .5988$

\begin{abstract}
The present observational, multicenter, retrospective study investigated the efficacy and tolerability of lacosamide in controlling secondary epileptic seizures in patients with brain tumors in Spain. Data from the medical records of patients $\geq 18$ years of age with brain tumors, who had received at least one dose of lacosamide for seizure management between July 2013 and November 2013, were collected. The primary and secondary objectives of the present study were to assess the effectiveness and tolerability of lacosamide. Data from 39 patients (mean age, 54.1 years; $66.7 \%$ male) were collected, where the two main reasons for initiation of lacosamide treatment were the lack of efficacy of other antiepileptic drugs (in $76.9 \%$ of patients) and the presence of adverse events (12.8\%) associated with other antiepileptic drugs. At the initiation of treatment, patients received a mean lacosamide dose of $138.5 \pm 68.3 \mathrm{mg} /$ day. At 6 months, lacosamide had significantly reduced the mean number of seizures from 26.4 (standard deviation [SD], 50.4) seizures for the 6 months prior to lacosamide initiation to a mean of 9.4 (SD, 22.8) seizures during the 6 months subsequent to lacosamide initiation; $\mathrm{P}<0.001$. Lacosamide was generally well tolerated; of the 25 patients who had complete safety data available at a 6-month follow-up, 3 patients (12\%) reported an adverse event, including dizziness, asthenia, instability and irritability. The present retrospective analysis suggested that lacosamide is an
\end{abstract}

Correspondence to: Dr Juan Manuel Sepúlveda-Sánchez, Neurooncology Unit, Hospital 12 de Octubre, Andalucía Avenue, 28041 Madrid, Spain

E-mail: juanmanuel.sepulveda@salud.madrid.org

Abbreviations: AEs, adverse events; AEDs, antiepileptic drugs; $\mathrm{SD}$, standard deviation

Key words: antiepileptic drugs, brain tumor, lacosamide, epilepsy effective and well-tolerated treatment in patients experiencing seizures due to brain tumors. Additional prospective studies with a larger patient population and randomized trial design are warranted.

\section{Introduction}

Epileptic seizures are a frequent and limiting complication in patients with brain cancer that can also occur in patients with systemic cancer (1-5). In total, $\leq 50 \%$ of patients with brain tumors are expected to have an epileptic seizure during the course of their disease (4). Seizure management is crucial in primary and metastatic brain tumors, but may be complicated (6). The main treatments available are antiepileptic drugs (AEDs). In patients with brain tumors who are experiencing seizures, the adverse events (AEs) and drug interactions associated with traditional AEDs are observed more frequently, compared with in the general population of patients with epilepsy $(6,7)$. A number of the traditional AEDs interact with corticosteroids, a universal treatment for brain tumors, reducing their efficacy (8-10). Certain AEDs also interact with cytochrome P450, causing the accelerated metabolism of the majority of chemotherapeutic agents $(11,12)$. Furthermore, the metabolism of AEDs can be altered by corticosteroids and chemotherapies, leading to under- and overdosing $(13,14)$. Therefore, it is essential to identify an AED that has proven efficacy, low and/or manageable toxicity with low drug-drug interactions and is easy to titrate.

Lacosamide is a third-generation AED that selectively enhances the slow inactivation of voltage-gated sodium channels (15). The drug is approved in the USA and EU for use as an adjunctive therapy, and in the USA for use as monotherapy in the treatment of focal epilepsies. The efficacy and tolerability of lacosamide is well established (16-18). Lacosamide has a favorable pharmacokinetic profile with low protein binding and a low potential for drug-drug interactions (15), and is available as an intravenous formulation.

To date, few studies have investigated the use of lacosamide in patients with epileptic seizures due to brain tumors. 
However, there is data from routine clinical practice that suggests promising efficacy and tolerability in this patient population: A retrospective chart review of 70 patients with brain tumors in the USA found that lacosamide was well tolerated and demonstrated effectiveness when used as an add-on AED treatment (19). The aim of the present study was to investigate the efficacy and tolerability of lacosamide in controlling epileptic seizures in patients with brain tumors in Spain.

\section{Materials and methods}

Study design and patients. This observational retrospective study was conducted at six centers in Spain: Hospital Provincial de Castellón (Castellón), Hospital 12 de Octubre (Madrid), Hospital General de Castellón (Castellón), Hospital Universitario Rey Juan Carlos (Madrid), University Hospital La Fe (Valencia) and Hospital Universitario Fundación Alcorcón (Madrid). Data from patients $\geq 18$ years of age who had received at least one dose of lacosamide for seizure management were collected. Criteria for study eligibility depended upon the attending neurologist's criteria, and included at least one convulsive seizure episode due to a brain tumor and subsequent placement on lacosamide as an anticonvulsant treatment. Resistance to previous AEDs was established following routine clinical practice procedures at each study center. Epilepsy was diagnosed based on the physician's clinical experience and symptoms indicative of epilepsy. All patients (or their guardian) provided written informed consent prior to inclusion in the present analysis. Patients were excluded if they were receiving any experimental drug other than lacosamide. The present study was conducted according to the principles of the Declaration of Helsinki and the study protocol was reviewed and approved by the Ethics Committee of Hospital Provincial de Castellón (Castellón, Spain).

Data collection. Data was collected by reviewing the medical records of patients and included patient demographics (age, gender, comorbidities, smoking status), tumor histology, functional status [as per the Eastern Cooperative Oncology Group criteria (20)], cancer treatment, seizure type, mean number of seizures and the number of previous and concomitant AEDs.

Treatment outcomes. The primary objective was to assess the effectiveness of lacosamide in patients with secondary epileptic seizures by comparing the number of seizures experienced by the patient prior to and subsequent to lacosamide treatment (at 3 and 6 months). An additional measure of efficacy was the need to progress to combination AED therapy [lacosamide + other AED(s)] to achieve seizure control. The secondary objective was to assess the tolerability of lacosamide (via reported AEs). The efficacy population included all patients who were still receiving lacosamide treatment at 3 months. All patients who received at least one dose of lacosamide during the study were included in the safety analysis. A subgroup analysis was performed to determine the efficacy and safety of lacosamide in patients who experienced a lack of efficacy from previous AEDs.

Statistical analysis. Statistical analyses for the present study were performed using the software package SAS version 9.3
(SAS Institute Inc., Cary, NC, USA). All variables were analyzed by summary statistical methods. For continuous variables, descriptive statistics including the arithmetic mean, standard deviation (SD), median, interquartile range and the minimum and maximum values were used. Continuous variable data were collected at the baseline, and at 3 and 6 months. For qualitative variables, absolute and relative frequency tables were generated. Continuous variables were assessed using the Student's t-test or the Wilcoxon signed-rank test when variables did not meet the normality criteria. For categorical variables, P-values were calculated using the $\chi^{2}$ test, or the Fisher's exact test when the criteria for the $\chi^{2}$ test were not fulfilled. $\mathrm{P}<0.05$ was considered to indicate a statistically significant difference.

Considering the patient characteristics, it was assumed that, following 3 months of lacosamide treatment, $16 \%$ of patients would exhibit a $\geq 50 \%$ decrease in the number of seizures. Based on this, a total of 47 evaluable patients were required to achieve an accuracy of $10 \%$, assuming a confidence level of $95 \%$. Another hypothesis examined in the present study was that lacosamide would produce a decrease of $\sim 30 \%$ in the number of seizures with an estimated standard deviation of $60 \%$. A sample of 46 patients was required to detect these differences as statistically significant using a Wilcoxon signed-rank test paired with a power of $90 \%$. However, only 39 patients were found eligible for the present study.

\section{Results}

Patient characteristics. Between July 2013 and November 2013, data from 39 patients with a brain tumor-associated epileptic seizure who had received lacosamide as an anticonvulsant were collected and included in the present analysis. The patients were distributed across the six medical centers as follows: Hospital Provincial de Castellón, n=8; Hospital 12 de Octubre, n=11; Hospital General de Castellón, n=2; Hospital Universitario Rey Juan Carlos, n=6; Hospital Universitari i Politècnic La Fe, n=4; Hospital Universitario Fundación Alcorcón, $\mathrm{n}=8$. Patients had a mean age of $54.1 \pm 13.8$ years and $66.7 \%$ were male (Table I). The majority of patients $(n=30$; $76.9 \%$ ) presented with a single brain lesion, and multiple brain lesions were reported in 9 (23.1\%) patients. Prior to the initiation of lacosamide treatment, patients had experienced a mean of 21.8 seizures (range, 0-200; SD 43.4) in the previous 3 months. The most common type of seizure experienced prior to treatment was a simple partial seizure. Of the 39 patients included in the study, 3- and 6-months of data were available for $33(84.6 \%)$ and $26(66.7 \%)$ patients, respectively (Table II). The reasons for the unavailable 6-month data in 13 patients were: Cancer-associated mortality $(n=7 ; 53.8 \%)$; change of address $(n=2)$; data not recorded $(n=2)$; withdrawal from the study prior to completion $(n=1)$; and lacosamide treatment withdrawn due to a lack of effectiveness $(n=1)$. A total of 30 patients were eligible for the subgroup analysis (Table I), from which 19 patients $(63.3 \%)$ completed the study. The reasons for the unavailability of 6-month data in the subgroup were: Cancer-associated mortality $(n=7)$, withdrawal from the study prior to completion $(n=3)$, and lost to follow-up $(n=1)$.

Lacosamide treatment. The main reason for the initiation of lacosamide treatment was the inefficacy of other prior 
Table I. Baseline characteristics and demographics.

\begin{tabular}{|c|c|c|}
\hline Characteristics $^{\mathrm{a}}$ & Main study $(\mathrm{n}=39)$ & Subgroup analysis $(n=30)$ \\
\hline Mean \pm SD age, years & $54.1 \pm 13.8$ & $52.9 \pm 13.9$ \\
\hline Male, n (\%) & $26(66.7)$ & $22(73.3)$ \\
\hline \multicolumn{3}{|l|}{ Smoking status, n (\%) } \\
\hline Smoker & $8(21.1)^{\mathrm{b}}$ & $5(17.2)^{\mathrm{b}}$ \\
\hline Ex-smoker & $9(23.7)^{\mathrm{b}}$ & $9(31.0)^{\mathrm{b}}$ \\
\hline \multicolumn{3}{|l|}{ Type of brain lesion, $\mathrm{n}(\%)$} \\
\hline Single & $30(76.9)$ & $22(73.3)$ \\
\hline Multiple & $9(23.1)$ & $8(26.7)$ \\
\hline \multicolumn{3}{|l|}{ Location of brain tumor, $\mathrm{n}(\%)$} \\
\hline Right & $16(42.1)^{\mathrm{b}}$ & $13(44.8)^{\mathrm{b}}$ \\
\hline Left & $16(42.1)^{\mathrm{b}}$ & $11(37.9)^{\mathrm{b}}$ \\
\hline Bilateral & $6(15.8)^{\mathrm{b}}$ & $5(17.2)^{\mathrm{b}}$ \\
\hline \multicolumn{3}{|l|}{ Specific location of brain tumor, $\mathrm{n}(\%)$} \\
\hline Lobar & $32(84.2)^{\mathrm{b}}$ & $25(86.2)^{\mathrm{b}}$ \\
\hline Callosum lobar + body & $2(5.3)^{b}$ & - \\
\hline Lobar + ganglia basal & $2(5.3)$ & $2(6.9)^{b}$ \\
\hline Other & $1(2.6)$ & $1(3.5)^{b}$ \\
\hline Lobar + other & $1(2.6)$ & $1(3.5)^{b}$ \\
\hline Tumor type, n (\%) & & - \\
\hline Primary & $31(81.6)$ & $22(75.9)^{\mathrm{b}}$ \\
\hline Metastases & $7(18.4)$ & $7(24.1)^{\mathrm{b}}$ \\
\hline \multicolumn{3}{|l|}{ Type of primary tumor in case of metastases, $\mathrm{n}(\%)$} \\
\hline Breast & $1(2.6)$ & $1(14.29)$ \\
\hline Lung $^{\mathrm{c}}$ & $4(10.3)$ & $4(57.1)$ \\
\hline Colon & $1(2.6)$ & $1(14.29)$ \\
\hline Melanoma & $1(2.6)$ & $1(14.29)$ \\
\hline \multicolumn{3}{|l|}{ Histological diagnosis, $\mathrm{n}(\%)$} \\
\hline Astrocytoma & $17(43.6)$ & $2(10.0)$ \\
\hline Oligodendroglioma & $8(20.5)$ & $5(25)$ \\
\hline Oligoastrocytoma & $1(2.6)$ & $1(5.0)$ \\
\hline Ependymoma & $1(2.6)$ & $1(5.0)$ \\
\hline Meningioma & $1(2.6)$ & $1(5.0)$ \\
\hline \multicolumn{3}{|l|}{ Type of secondary seizure, n (\%) } \\
\hline Post-traumatic & $1(2.6)$ & $1(3.3)$ \\
\hline Neoplastic & $38(97.4)$ & $29(96.7)$ \\
\hline Status epilepticus, n (\%) & $10(25.6)$ & $7(23.3)$ \\
\hline Convulsive & $7(17.9)$ & $5(71.4)$ \\
\hline Non-convulsive & $3(7.7)$ & $2(28.6)$ \\
\hline \multicolumn{3}{|l|}{ Type of seizure, n (\%) } \\
\hline Generalized & $5(13.5)$ & $2(7.1)^{\mathrm{d}}$ \\
\hline Simple partial & $22(59.5)$ & $18(64.3)^{\mathrm{d}}$ \\
\hline Complex partial & $3(8.1)$ & $2(7.1)^{\mathrm{d}}$ \\
\hline Generalized + simple partial & $3(8.1)$ & $3(10.7)^{\mathrm{d}}$ \\
\hline Generalized + complex partial & $1(2.7)$ & $1(3.6)^{\mathrm{d}}$ \\
\hline Generalized + simple partial + complex partial & $3(8.1)$ & $2(7.1)^{\mathrm{d}}$ \\
\hline \multicolumn{3}{|l|}{ Previous AED, n (\%) } \\
\hline Phenytoin & $7^{\mathrm{e}}(18.0)$ & $5(16.7)$ \\
\hline Valproic acid & $11(28.2)$ & $8(26.7)$ \\
\hline Carbamazepine & $5(12.8)$ & $3(10.0)$ \\
\hline Oxcarbazepine & $2(5.1)$ & $2(6.7)$ \\
\hline
\end{tabular}


Table I. Continued.

\begin{tabular}{lcc}
\hline Characteristics $^{\mathrm{a}}$ & Main study $(\mathrm{n}=39)$ & Subgroup analysis $(\mathrm{n}=30)$ \\
\hline Levetiracetam & $34(87.2)$ & $27(90.0)$ \\
Gabapentin & $1(2.6)$ & $1(3.3)$ \\
Topiramate & $1(2.6)$ & $1(3.3)$ \\
Eslicarbazepine acetate & $2(5.1)$ & $2(6.7)$ \\
Comorbidities, n (\%) & & \\
Hypertension & $11(29.7)$ & $9(32.1)$ \\
Dyslipidemia & $7(18.4)$ & $6(20.7)$ \\
Diabetes & $3(8.3)$ & $3(11.1)$ \\
\hline
\end{tabular}

${ }^{\mathrm{a}} \mathrm{All}$ values are numbers (proportion of patients) unless otherwise stated. ${ }^{\mathrm{b}}$ Data was unavailable for 1 patient. ${ }^{\mathrm{c} I n c l u d e s}$ neuroendocrine lung cancer, non-small cell lung cancer and lung cell adenocarcinoma. ${ }^{\mathrm{d} D a t a}$ was unavailable for 2 patients. ${ }^{\mathrm{e}} \mathrm{A}$ number of patients received more than one AED at baseline. AED, antiepileptic drug; SD, standard deviation.

AEDs (76.9\% of patients), followed by a lack of tolerance to previous AEDs (12.8\%). At the initiation of treatment, patients received a mean dose of $138.5 \pm 68.3 \mathrm{mg}$ /day of lacosamide. The majority $(66.7 \%)$ of patients initiated treatment at a dose of $100 \mathrm{mg} /$ day. The most commonly used AEDs at the initiation of lacosamide treatment were levetiracetam $(84.6 \%$ of patients) and valproic acid (20.5\%).

While receiving lacosamide, nine patients modified their lacosamide treatment; seven due to a lack of efficacy and two due to AEs. Of these, lacosamide was discontinued in one patient due to dermal toxicity, which improved subsequent to the discontinuation of lacosamide. The remaining lacosamide modifications were an increase in dose. Two patients reported a lack of efficacy with lacosamide and one other patient reported unacceptable AEs; however, the dose of lacosamide those patients received remained unchanged.

In the subgroup analysis, the mean dose of lacosamide was $123.3 \pm 55.29 \mathrm{mg} /$ day, with the majority of patients $(70 \%)$ receiving an initial dose of $100 \mathrm{mg} /$ day. The most frequently used AEDs with lacosamide in the subgroup were levetiracetam $(93.33 \%)$ and valproic acid (23.33\%).

Concomitant medications. Table III depicts the concomitant treatments received by the patients during the study period. The most common concomitant AED administered during the present study with lacosamide treatment was levetiracetam ( $94.3 \%$ of patients). A total of 8 patients modified their concomitant AEDs over the study period. A total of 4 patients reduced their levetiracetam dose; 1 patient discontinued carbamazepine and reduced their dose of valproic acid; 1 patient initiated treatment with eslicarbazepine acetate and carbamazepine (which was later discontinued); 1 patient initiated treatment with valproic acid; 1 patient reduced the dose of valproic acid.

A total of 18 patients also received concomitant treatment with a corticosteroid during the study period (Table III). Patients who received dexamethasone modified their concomitant treatment: 5 patients reduced their dose and 1 patient increased the dose. No additional modifications to the concomitant corticosteroid treatment were made during the study period. No drug-interaction between lacosamide and radiotherapy, or lacosamide and chemotherapy was observed.

In the subgroup analysis, all patients received lacosamide in combination with another drug. The numbers of concomitant treatments used were 1, 2, 4 and 6 in 60, 33.33, 3.33 and $3.33 \%$ of patients, respectively. A total of 29 patients $(96.7 \%)$ received levetiracetam and lacosamide. Table III details the anticancer therapy received by each of the patients included in the subgroup analysis. No interaction between lacosamide and chemotherapy or radiotherapy was reported.

Treatment effectiveness. The number of seizures from the initiation of treatment to 3 months [mean 6.8, SD 19.8; median 0.0 (range $0.0-100.0$ )] was significantly lower compared with the number of seizures in the 3 months prior to lacosamide initiation [mean 22.9, SD 44.5; P<0.0001; Fig. 1; median 3.0 (range 0.0-200.0)], for the 33 patients with data available after 3 months of treatment. The majority of seizures experienced in the first 3 months of lacosamide treatment were simple partial seizures followed by complex partial seizures. No patient experienced generalized seizures in the first 3 months of lacosamide treatment (Fig. 1). Similar results were observed after 6 months. Compared with the 6 months prior to lacosamide initiation, there was a significant reduction in total seizures at 6 months [prior to treatment, mean 26.4, SD 50.4, median 4.0 (range 0-200); at 6 months, mean 9.4, SD 22.8, median 0.5 (range 0-100); difference in means $\mathrm{P}<0.0001$; Fig. 2].

Subsequent to 3 and 6 months of lacosamide treatment, the majority of patients exhibited a reduction in the number of seizures they experienced $(72.7$ and $56.5 \%$ of patients, respectively), with 87.5 and $84.6 \%$ of patients experiencing a reduction in seizure frequency of $\geq 50 \%$. Furthermore, at the end of the study period, 14 patients $(53.8 \%)$ reported having no seizures during treatment.

At 3 months, only 5 patients (15.2\%) demonstrated no reduction in their seizure frequency following lacosamide initiation, and 4 patients $(12.1 \%)$ had an increase in seizure frequency. Of these 9 patients who did not respond to lacosamide therapy, 3 were revealed to have cancer progression. 
Table II. Histological diagnosis, oncology treatment and the number of seizures reported in the study patients prior to and subsequent to lacosamide treatment.

\begin{tabular}{|c|c|c|c|c|c|}
\hline $\begin{array}{l}\text { Case } \\
\text { no. }\end{array}$ & $\begin{array}{l}\text { Histological } \\
\text { diagnosis }\end{array}$ & $\begin{array}{l}\text { Oncology } \\
\text { treatment }\end{array}$ & $\begin{array}{l}\text { Seizures of the } \\
3 \text { months prior } \\
\text { to treatment, } \mathrm{n}\end{array}$ & $\begin{array}{l}\text { Seizures during } \\
\text { first } 3 \text { months } \\
\text { of treatment, } \mathrm{n}\end{array}$ & $\begin{array}{l}\text { Seizures during } \\
\text { months 3-6 } \\
\text { of treatment, } n\end{array}$ \\
\hline 1 & Glioblastoma & - & 2 & 0 & - \\
\hline 2 & Glioblastoma & Other & 0 & 0 & 0 \\
\hline 3 & Pulmonary neuroendocrine tumor & Radiotherapy & 2 & 0 & - \\
\hline 4 & Non-small cell lung cancer & - & 3 & - & - \\
\hline 5 & Pulmonary adenocarcinoma & Other & 3 & 5 & - \\
\hline 6 & Melanoma & - & 3 & - & - \\
\hline 7 & Glioblastoma & - & 3 & 0 & - \\
\hline 8 & Glioblastoma & - & 3 & 0 & - \\
\hline 9 & Oligodendroglioma grade II & Chemotherapy & 7 & 60 & 58 \\
\hline 10 & Glioblastoma & - & 12 & 4 & 8 \\
\hline 11 & Oligodendroglioma grade III & Chemotherapy & 1 & 0 & 1 \\
\hline 12 & - & - & 2 & 0 & 0 \\
\hline 13 & Glioblastoma & Other & 27 & 3 & - \\
\hline 14 & Astrocytoma grade II & Radiotherapy & 93 & 0 & 6 \\
\hline 15 & Glioblastoma & - & 0 & 0 & 0 \\
\hline 16 & Astrocytoma grade II & Other & 6 & 0 & - \\
\hline 17 & Glioblastoma & Other & 34 & 5 & - \\
\hline 18 & Oligodendroglioma grade III & Chemotherapy & 0 & 0 & 1 \\
\hline 19 & Glioblastoma & - & 0 & 0 & 0 \\
\hline 20 & High grade glioma & - & 90 & 0 & 0 \\
\hline 21 & - & - & 1 & 5 & 2 \\
\hline 22 & Oligodendroglioma & $\begin{array}{l}\text { Radiotherapy, } \\
\text { Chemotherapy }\end{array}$ & 1 & 1 & 4 \\
\hline 23 & Frontal parietal oligodendroglioma & Chemotherapy & - & - & 6 \\
\hline 24 & Oligodendroglioma IL 1P 19Q & Chemotherapy & 3 & 0 & 0 \\
\hline 25 & Infiltrating ductal breast cancer & Radiotherapy & & 3 & 0 \\
\hline 26 & Non-small cell lung cancer & $\begin{array}{l}\text { Radiotherapy, } \\
\text { Palliative care }\end{array}$ & 2 & - & - \\
\hline 27 & Right frontal glioblastoma & - & - & - & - \\
\hline 28 & Ependimoma & Other & 12 & 5 & - \\
\hline 29 & Glioma grade II & Radiotherapy & 200 & 12 & 12 \\
\hline 30 & - & $\begin{array}{l}\text { Radiotherapy, } \\
\text { Chemotherapy }\end{array}$ & - & - & - \\
\hline 31 & - & - & 4 & 0 & 0 \\
\hline 32 & Astrocytoma grade II & Other & 63 & 0 & 12 \\
\hline 33 & Glioblastoma & - & 3 & 2 & 0 \\
\hline 34 & Oligodendroglioma grade II & Other & 130 & 100 & 100 \\
\hline 35 & Oligodendroglioma grade II & Other & 15 & 1 & 0 \\
\hline 36 & Oligoastrocytoma grade II & - & 4 & 0 & 0 \\
\hline 37 & Colon & Palliative care & 3 & 0 & 0 \\
\hline 38 & Glioblastoma & - & 20 & 13 & - \\
\hline 39 & Meningioma & Other & 10 & 4 & 15 \\
\hline
\end{tabular}

Overall, 10 patients were considered to have disease progression during the study, the 7 patients who succumbed to the cancer and aforementioned 3 patients.

Finally, during the study, 10 patients experienced status epilepticus ( 7 convulsive and 3 non-convulsive) and were treated with levetiracetam $(n=6)$, lacosamide $(n=4)$, valproic acid $(n=6)$ phenytoin $(n=3)$ and clonazepam $(n=1)$.

In the subgroup analysis, the mean number of seizures following 3 months of lacosamide treatment (mean 8.9, SD 22.5) was significantly lower compared with the mean 
Table III. Concomitant treatments received during the 6 months of lacosamide treatment.

\begin{tabular}{|c|c|c|}
\hline Treatment & $\begin{array}{l}\text { Main } \\
\text { study, } \\
\text { n (\%) }\end{array}$ & $\begin{array}{c}\text { Subgroup } \\
\text { analysis, } \\
\mathrm{n}(\%)\end{array}$ \\
\hline Surgery only & $7(17.9)$ & - \\
\hline Radiotherapy + chemotherapy ${ }^{\mathrm{a}}$ & $6(15.4)$ & $5(16.7)$ \\
\hline Chemotherapy only ${ }^{\mathrm{a}}$ & $11(28.2)$ & $13(43.3)$ \\
\hline Radiotherapy only ${ }^{\mathrm{a}}$ & $6(15.4)$ & $3(10.0)$ \\
\hline None & $16(41.0)$ & $9(30.0)$ \\
\hline \multicolumn{3}{|l|}{$\begin{array}{l}\text { Chemotherapies received } \\
\text { during the study }\end{array}$} \\
\hline Temozolomide & $19(48.7)$ & - \\
\hline Bevacizumab & $5(12.8)$ & - \\
\hline Dacomitinib & $3(7.7)$ & - \\
\hline Carboplatin & $1(2.6)$ & - \\
\hline Carmustine & $1(2.6)$ & - \\
\hline Fotemustine & $1(2.6)$ & - \\
\hline Irinotecan & $1(2.6)$ & - \\
\hline Lomustine & $1(2.6)$ & - \\
\hline Paclitaxel & $1(2.6)$ & - \\
\hline Pamidronic acid & $1(2.6)$ & - \\
\hline Procarbazine & $1(2.6)$ & - \\
\hline Vincristine & $1(2.6)$ & - \\
\hline $\begin{array}{l}\text { Corticosteroids received } \\
\text { during the study }\end{array}$ & & - \\
\hline Dexamethasone & $16(41.0)$ & - \\
\hline Prednisolone & $1(2.6)$ & - \\
\hline Fluticasone & $1(2.6)$ & - \\
\hline Lacosamide monotherapy & $4(10.3)$ & - \\
\hline Lacosamide + one AED & $20(51.3)$ & - \\
\hline Lacosamide + levetiracetam & $19(48.7)$ & - \\
\hline Lacosamide + carbamazepine & $1(2.6)$ & - \\
\hline Lacosamide + two AEDs & $13(33.3)$ & - \\
\hline Lacosamide + levetiracetam & $12(30.8)$ & - \\
\hline Lacosamide + valproic acid & $8(20.5)$ & - \\
\hline Lacosamide + phenytoin & $3(7.7)$ & - \\
\hline Lacosamide + carbamazepine & $2(5.1)$ & - \\
\hline $\begin{array}{l}\text { Lacosamide + eslicarbazepine } \\
\text { acetate }\end{array}$ & $1(2.6)$ & - \\
\hline Lacosamide + four AEDs & $2(5.1)$ & - \\
\hline
\end{tabular}

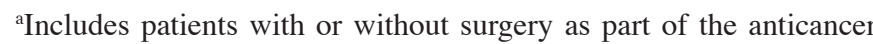
treatment. AEDs, antiepileptic drugs.

number of seizures at the baseline (mean 27.4, SD 49.1; $\mathrm{P}<0001)$. The median number of seizures at 3 months was 2.0 (range $0.0-100.0$ ) vs. 6.0 (range $0.0-200.0$ ) at baseline. The majority of seizures experienced subsequent to 3 months of treatment were partial seizures followed by partial complex seizures. No generalized seizures were reported at 3 months subsequent to lacosamide treatment. After 3 months of lacosamide treatment, $80 \%$ of patients exhibited a decrease in the

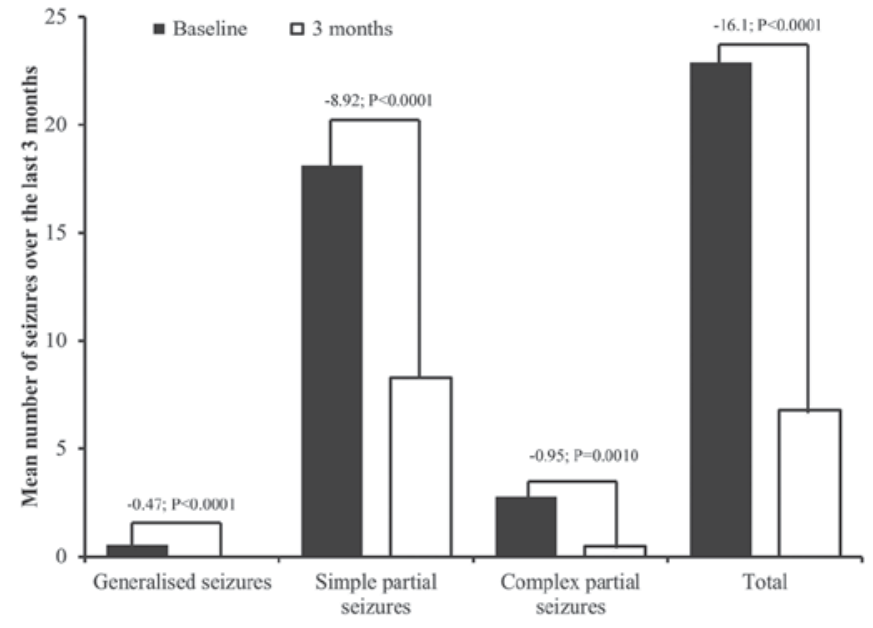

Figure 1. Mean number of seizures in the 3 months prior to, and during the 3 months of lacosamide treatment in patients experiencing epileptic seizures due to a brain tumor $(\mathrm{n}=33)$. Numbers above the bars indicate the difference from the baseline and the corresponding P-value (calculated using the $\chi^{2}$ test).

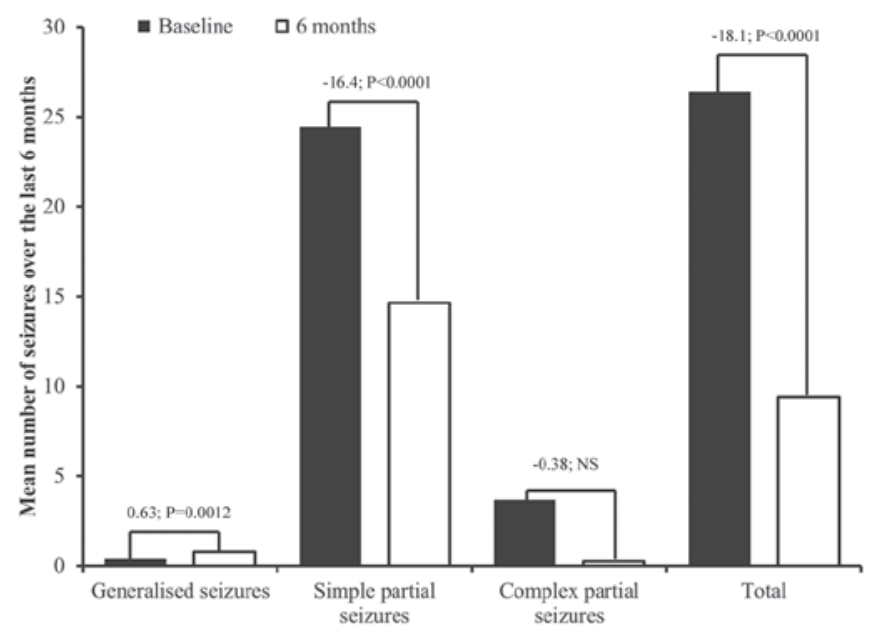

Figure 2. Mean number of seizures in the 6 months prior to, and during the 6 months of lacosamide treatment in patients experiencing epileptic seizures due to a brain tumor $(n=26)$. Numbers above the bars indicate the difference from the baseline and the corresponding P-value (calculated using the $\chi^{2}$ test). NS, not significant.

number of seizures, with $>50 \%$ of reduction observed in $85 \%$ of these patients. Similarly, after 6 months of lacosamide treatment, the number of seizures (mean 12.2, SD 26.6) was lower compared with those reported at baseline (mean 32.9, SD 56.8; $\mathrm{P}=0.0004)$. The median number of seizures at 6 months was 0.0 (range $0.0-100.0$ ) vs. 6.5 (range 0.0-200.0) at baseline. In addition, after 6 months of treatment, $68.75 \%$ of patients exhibited a reduction in the number of seizures, with $81.82 \%$ of these patients reporting a $>50 \%$ reduction.

Safety. Lacosamide was generally well tolerated. Of the 25 patients who had complete safety data available at the 6-month follow-up, 3 patients (12\%) reported an AE, including dizziness $(n=1)$, asthenia $(n=2)$, instability $(n=1)$, irritability $(n=1)$ and leg edema $(n=1)$. None of these events were considered severe. No neurocognitive deficits, cardiac adverse effects or liver function 
test abnormalities were reported with the lacosamide treatment. Furthermore, no AEs were reported that were considered to be associated with anticancer-treatment. The subgroup analysis also demonstrated that lacosamide treatment was well tolerated over the 6-month treatment period.

\section{Discussion}

This non-interventional, observational retrospective analysis investigated the effectiveness and safety of lacosamide for the treatment of epileptic seizures due to brain tumors. The findings demonstrated that lacosamide significantly reduced the total number of seizures and was well tolerated in this patient population.

In the present study, lacosamide significantly reduced the mean number of seizures experienced over a 6-month period by a mean of 18.1 events. A large majority of patients in the current study had a reduction in the number of seizures they experienced, with $84.6 \%$ of patients experiencing a reduction in seizure frequency of $\geq 50 \%$ after 6 months of lacosamide treatment. Furthermore, at the end of the study period, 14 patients $(40.0 \%)$ reported having no seizures whilst receiving lacosamide treatment. These efficacy results are consistent with those of clinical trials of lacosamide in patients with epilepsy, which previously demonstrated that lacosamide effectively reduces seizure frequency compared with a placebo $(16-18,21)$. It is noteworthy that the $50 \%$ responder rate observed in this study was larger compared with those reported in the major phase III trials of lacosamide (33-41.2\% of patients), despite larger doses of lacosamide administered in the phase III trials. However, it is important to note that the patients included in the phase III trials were more refractory to treatment (with a mean duration of epilepsy of 23 years) compared with the patients included in the present study.

In the present study, lacosamide was generally well tolerated, with only 3 patients (12\%) reporting an AE over the 6-month treatment period. The AEs reported in this study included dizziness, asthenia, instability, irritability and leg edema. These results are consistent with clinical trials of lacosamide in patients with epilepsy, which indicated that the most common AEs associated with lacosamide involve the nervous or gastrointestinal systems, and include dizziness, headache, fatigue, nausea and diplopia $(16-18,22,23)$. The present study had a lower frequency of AEs compared with that reported in clinical trials (range, $70-80 \%$ of patients who received 200 or $400 \mathrm{mg}$ of lacosamide/day) $(22,23)$; however, the smaller number of patients may explain this. Notably, none of the neurocognitive deficits typically associated with the use of AEDs in patients with brain tumors were reported (24). Furthermore, no cardiac adverse effects or liver function test abnormalities were reported following lacosamide treatment.

To the best of our knowledge, only a limited number of other studies have investigated the efficacy and safety of lacosamide in a similar patient population $(19,25)$. The findings of the present study are in accordance with the results of the retrospective analysis conducted by Saria et al (19), which investigated the efficacy and safety of lacosamide as an add-on AED in 70 patients with primary brain tumors who received lacosamide for seizure activity. Similar to the present study, Saria et al (19) demonstrated that lacosamide was effective and reduced the frequency of seizures in $\sim 66 \%$ of patients; lacosamide was additionally demonstrated to be well tolerated, with $77 \%$ of patients in the study reporting no toxicity (19). Maschio et al (25) published a preliminary report of the efficacy and tolerability of lacosamide as an add-on therapy in 14 patients with brain tumor-associated epilepsy. The results from the present study were consistent with the findings of Maschio et al, which indicated that lacosamide was effective and well tolerated (25). Therefore, in the present patient population, lacosamide may provide a valid alternative to other AEDs as an add-on therapy.

In patients with epilepsy due to brain tumors, the ideal AED would provide complete seizure control while avoiding significant AEs and drug-drug interactions, particularly as patients with brain tumors are often receiving treatments for their cancer and experiencing chemotherapy-associated AEs (2). However, there is a high risk of drug-drug interactions between anticancer agents and AEDs, particularly when using traditional enzyme-inducing AEDs (26). However, since the advent of second- and third-generation AEDs, a number of newer AEDs have demonstrated reduced drug-drug interactions, including lacosamide, gabapentin, levetiracetam and pregabalin (27). Based on the reported interactions of lacosamide with AEDs and other drugs, and its pharmacokinetic profile, we hypothesize that lacosamide may be an ideal anticonvulsant for patients with brain tumors. The results of the present study support this hypothesis, particularly as no serious drug interactions were observed during the follow-up period.

There are a number of restrictions to the present study, including the inherent limitations of the retrospective, non-controlled study design. Due to the small sample size, the confidence intervals around the point estimates obtained were correspondingly large. Also, the effect of tumor status and concomitant tumor treatment on the reduction in the number of seizures during 6 months of lacosamide treatment cannot be ruled out. As aforementioned, the efficacy and tolerability of lacosamide has been well established in a large group of patients with partial-onset seizures enrolled in three, randomized, multicenter placebo-controlled clinical trials (16-18). However, little information on the use of lacosamide in patients with brain cancer is available; thus, the present study was designed to clarify the efficacy and safety of lacosamide in this group of patients. While this is a retrospective study without a control group, data obtained in this analysis provides useful information on the efficacy and tolerability of lacosamide in patients with a high level of morbidity that are receiving multiple drugs and are thus susceptible to drug-interaction complications.

In conclusion, epilepsy is an important risk factor for long-term disability in patients with brain tumors. The present retrospective analysis suggests that lacosamide is an effective and well-tolerated treatment for patients with brain tumors who experience seizures, and additional prospective studies with a larger patient population and randomized trial design are warranted.

\section{Acknowledgements}

The authors would like to thank Ms. Ana Gentil (Pertica, Castellón, Spain) for performing the statistical analysis and Ms. Simone Boniface (Springer Healthcare Communications, 
Auckland, New Zealand), for assistance with medical writing. The present study was developed with the support of the Foundation of the Provincial Hospital of Castellón.

\section{Conflicts of interest}

Antonio Belenguer has received research grants from funding agencies (Fundación Grupo ERESA), honoraria for speaking at symposia (including from Sanofi Genzyme, Teva Pharmaceutical Industries, Ltd. and Merck KGaA) and financial support for attending symposia (including from Biogen, Inc. and Sanofi Genzyme). In addition, Antonio Belenguer has served on advisory boards, the board of directors and further managerial positions in the Agència Valenciana de Salut. Antonio Conde-Moreno has received honoraria for speaking at symposia (including from Janssen and Astellas).

\section{References}

1. Hildebrand J, Lecaille C, Perennes J and Delattre JY: Epileptic seizures during follow-up of patients treated for primary brain tumors. Neurology 65: 212-215, 2005.

2. Rossetti AO and Stupp R: Epilepsy in brain tumor patients. Curr Opin Neurol 23: 603-609, 2010.

3. Singh G, Rees JH and Sander JW: Seizures and epilepsy in oncological practice: Causes, course, mechanisms and treatment. J Neurol Neurosurg Psychiatry 78: 342-349, 2007.

4. van Breemen MS, Wilms EB and Vecht CJ: Epilepsy in patients with brain tumours: Epidemiology, mechanisms, and management. Lancet Neurol 6: 421-430, 2007.

5. Rudà R and Soffietti R: What is new in the management of epilepsy in gliomas? Curr Treat Options Neurol 17: 351, 2015.

6. Schiff D, Lee EQ, Nayak L, Norden AD, Reardon DA and Wen PY: Medical management of brain tumors and the sequelae of treatment. Neuro Oncol 17: 488-504, 2015.

7. Smith KC: The management of seizures in brain tumor patients. J Neurosci Nurs 42: 28-39, 2010.

8. Haque N, Thrasher K, Werk EE Jr, Knowles HC Jr and Sholiton LJ: Studies on dexamethasone metabolism in man: Effect of diphenylhydantoin. J Clin Endocrinol Metab 34: 44-50, 1972.

9. Gambertoglio JG, Holford NH, Kapusnik JE, Nishikawa R, Saltiel M, Stanik-Lizak P, Birnbaum JL, Hau T and Amend WJ Jr: Disposition of total and unbound prednisolone in renal transplant patients receiving anticonvulsants. Kidney Int 25: 119-123, 1984

10. Chalk JB, Ridgeway K, Brophy T, Yelland JD and Eadie MJ: Phenytoin impairs the bioavailability of dexamethasone in neurological and neurosurgical patients. J Neurol Neurosurg Psychiatry 47: 1087-1090, 1984.

11. Warren RD and Bender RA: Drug interactions with antineoplastic agents. Cancer Treat Rep 61: 1231-1241, 1977.

12. Rudà R, Bello L, Duffau H and Soffietti R: Seizures in low-grade gliomas: Natural history, pathogenesis, and outcome after treatments. Neuro Oncol 14 (Suppl 4): iv55-iv64, 2012.
13. Fincham RW and Schottelius DD: Decreased phenytoin levels in antineoplastic therapy. Ther Drug Monit 1: 277-283, 1979.

14. Perucca E and Pisani F: Pharmacokinetics and interactions of the new antiepileptic drugs. Epilepsy Res Suppl 3: 79-88, 1991.

15. Beydoun A, D'Souza J, Hebert D and Doty P: Lacosamide: Pharmacology, mechanisms of action and pooled efficacy and safety data in partial-onset seizures. Expert Rev Neurother 9: 33-42, 2009.

16. Ben-Menachem E, Biton V, Jatuzis D, Abou-Khalil B, Doty P and Rudd GD: Efficacy and safety of oral lacosamide as adjunctive therapy in adults with partial-onset seizures. Epilepsia 48: 1308-1317, 2007.

17. Chung S, Sperling MR, Biton V, Krauss G, Hebert D, Rudd GD and Doty P; SP754 Study Group: Lacosamide as adjunctive therapy for partial-onset seizures: A randomized controlled trial. Epilepsia 51: 958-967, 2010.

18. Halász P, Kälviäinen R, Mazurkiewicz-Beldzińska M, Rosenow F, Doty P, Hebert D and Sullivan T; SP755 Study Group: Adjunctive lacosamide for partial-onset seizures: Efficacy and safety results from a randomized controlled trial. Epilepsia 50: 443-453, 2009.

19. Saria MG, Corle C, Hu J, Rudnick JD, Phuphanich S, Mrugala MM, Crew LK, Bota DA, Dan Fu B, Kim RY, et al: Retrospective analysis of the tolerability and activity of lacosamide in patients with brain tumors: Clinical article. J Neurosurg 118: 1183-1187, 2013.

20. Oken MM, Creech RH, Tormey DC, Horton J, Davis TE, McFadden ET and Carbone PP: Toxicity and response criteria of the eastern cooperative oncology group. Am J Clin Oncol 5: 649-655, 1982

21. Pellerino A, Magistrello M, Franchino F, Nicolotto E, Soffietti R and Rudà R: Efficacy and tolerability of lacosamide in patients with glioma: A prospective study. Eur J Neurol 22 (Suppl 1): 73, 2015.

22. European Medicines Agency: Lacosamide (Vimpat $50 \mathrm{mg}$ tablets): Summary of product characteristics [online]. Available from URL: http://www.ema.europa. eu/docs/en_GB/document_library/EPAR - Product

Information/human/000863/WC500050338.pdf [Accessed 2016 May 20].

23. US Food and Drug Administration: Vimpat (lacosamide) tablets and injection: US prescribing information [online]. Available from URL: http://www.accessdata.fda.gov/drugsatfda_docs/label/2008/0222531bl.pdf [Accessed 2016 May 20].

24. Klein M, Engelberts NH, van der Ploeg HM, Kasteleijn-Nolst Trenité DG, Aaronson NK, Taphoorn MJ, Baaijen $\mathrm{H}$, Vandertop WP, Muller M, Postma TJ and Heimans JJ: Epilepsy in low-grade gliomas: The impact on cognitive function and quality of life. Ann Neurol 54: 514-520, 2003.

25. Maschio M, Dinapoli L, Mingoia M, Sperati F, Pace A, Pompili A, Carapella CM, Vidiri A and Muti P: Lacosamide as add-on in brain tumor-related epilepsy: Preliminary report on efficacy and tolerability. J Neurol 258: 2100-2104, 2011.

26. Yap KY, Chui WK and Chan A: Drug interactions between chemotherapeutic regimens and antiepileptics. Clin Ther 30: 1385-1407, 2008.

27. Johannessen Landmark C and Patsalos PN: Drug interactions involving the new second- and third-generation antiepileptic drugs. Expert Rev Neurother 10: 119-140, 2010. 